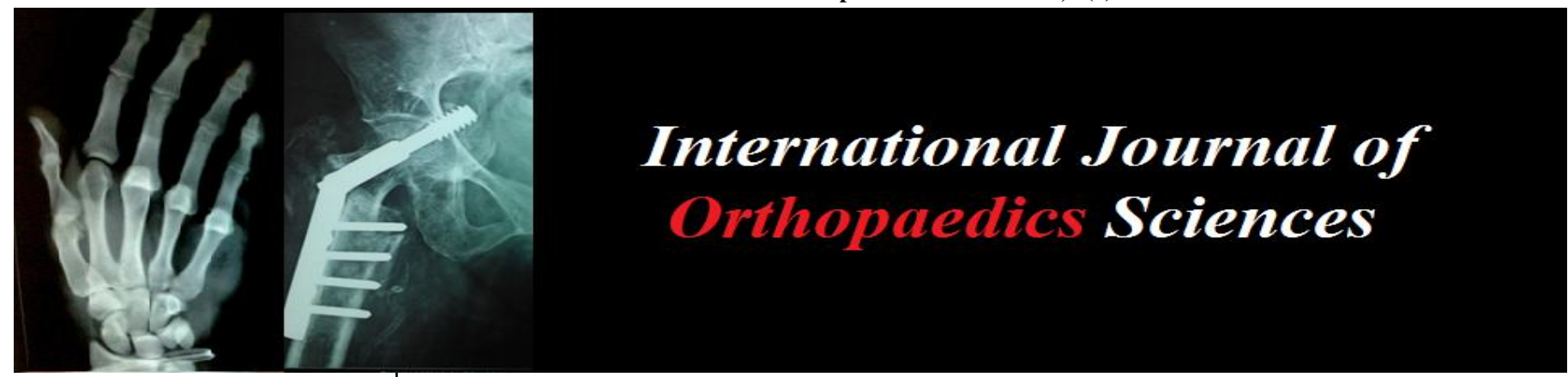

ISSN: $2395-1958$

IJOS 2017; 3(3): 317-319

(C) 2017 IJOS

www.orthopaper.com

Received: 26-05-2017

Accepted: 28-06-2017

Dr. Suresh Padya

Assistant professor, MIMS

Nellimarla, Vizianagaram,

Andhra Pradesh, India

Gopisetty Chaitanya kishore

Postgraduate, CAIMS,

Karimnagar, Telangana, India

Sai Veerla

Postgraduate, CAIMS,

Karimnagar, Telangana, India

Prakash Mukara

Postgraduate, CAIMS,

Karimnagar, Telangana, India

Mahesh

Postgraduate, CAIMS,

Karimnagar, Telangana, India

Correspondence

Dr. Suresh Padya

Assistant Professor, MIMS,

Nellimarla, Vizianagaram,

Andhra Pradesh, India

\section{Surgical management of closed tendoachilles ruptures and evaluation of results}

\author{
Dr. Suresh Padya, Gopisetty Chaitanya Kishore, Sai Veerla, Prakash \\ Mukara and Mahesh
}

DOI: $\underline{\text { http://dx.doi.org/10.22271/ortho.2017.v3.i3e.59 }}$

\section{Abstract}

Aim and Objective: To study surgical management of closed ruptures of tendoachilles by different surgical techniques, their complications, and functional outcome after surgery.

Method: prospective data collection performed on patients aged 15-45 years who were treated for closed tendoachilles ruptures by various surgical techniques over a period of 2 years.

Results: According to Quigley's scoring system $60 \%$ had excellent result, 25\% had good results, 10\% had fair results, $5 \%$ had poor results.

Conclusion: Ruptures were most common in patients with heel pain with trivial and blunt injury mostly degenerative tears. Most ruptures occurred in Zone I. Both Flexor hallucis longus and Peroneus brevis transfers yielded good to excellent results in chronic ruptures $>4$ weeks old, and with $>3 \mathrm{~cm}$ gap. End to End repair yielded good to excellent result with $<4$ weeks old and defects less than $3 \mathrm{~cm}$.

Keywords: Tendoachilles rupture; surgical treatment, Quigley's scoring; FHL transfer; peroneus brevis transfer; end to end repair

\section{Introduction}

The Achilles tendon is the strongest and thickest tendon in the body. Achilles tendon ruptures are most common tendon rupture in lower extremity account for nearly $40 \%$ of all operated tendon ruptures. Loss of Achilles function causes a significant loss in plantar flexion strength, which in turn can lead to an inability to run, stand on tip toes, play sports, and difficulty in climbing stairs.

Most of closed ruptures are degenerative ruptures, delay in presentation to the hospital. Surgical treatment often involves the need to restore continuity to tendon ends that may have retracted leading to irreducible gaps. Restoration of the physiologic tension of the gastrocnemius-soleus complex is the goal of surgical intervention.

\section{Materials and methods}

It is a Prospective study done during 2014 to 2016, the total number of 20 patients were seen from November 2014 to October 2016 with closed tendoachilles rupture and were taken for study and pattern of presentation and problems in management

Results

Age incidence

\begin{tabular}{|c|c|c|}
\hline Age & No. of Cases & Percentage \\
\hline $21-30$ & 2 & $10.00 \%$ \\
\hline $31-40$ & 1 & $5.00 \%$ \\
\hline $41-50$ & 6 & $30.00 \%$ \\
\hline $51-60$ & 11 & $55.00 \%$ \\
\hline
\end{tabular}


Sex incidence

\begin{tabular}{|c|c|c|}
\hline Sex & No. of Cases & Percentage \\
\hline Male & 15 & $75.00 \%$ \\
\hline Female & 5 & $25.00 \%$ \\
\hline
\end{tabular}

Aetiology

\begin{tabular}{|c|c|c|}
\hline Cause & No. of Cases & Percentage \\
\hline Local steroid injection & 6 & $30.00 \%$ \\
\hline Trauma trivial and blunt trauma & 14 & $70.00 \%$ \\
\hline
\end{tabular}

\section{Site of Rupture}

\begin{tabular}{|c|c|c|}
\hline Size of Rupture & No. of Cases & Percentage \\
\hline Zone I & 13 & $65.00 \%$ \\
\hline Zone II & 7 & $35.00 \%$ \\
\hline Zone III & 0 & $0.000 \%$ \\
\hline
\end{tabular}

\section{Procedure Performed}

\begin{tabular}{|c|c|c|}
\hline Procedure Done & No. of Cases & Percentage \\
\hline End to end repair & 8 & $40.00 \%$ \\
\hline Peroneus brevis transfer & 6 & $30.00 \%$ \\
\hline Flexor hallucis longus transfer & 6 & $30.00 \%$ \\
\hline
\end{tabular}

\section{Complications}

\begin{tabular}{|c|c|c|}
\hline Complication & No. of Cases & Percentage \\
\hline Superficial infection & 5 & $25.00 \%$ \\
\hline Scar hypertrophy & 1 & $5.00 \%$ \\
\hline Deep infection & 1 & $5.00 \%$ \\
\hline Scar dehiscence & 1 & $5.00 \%$ \\
\hline
\end{tabular}

Quigley's Scoring System ${ }^{[1]}$

\begin{tabular}{|c|c|c|}
\hline Result & No. of Cases & Percentage \\
\hline Excellent & 12 & $60.00 \%$ \\
\hline Good & 5 & $25.00 \%$ \\
\hline Fair & 2 & $10.00 \%$ \\
\hline Poor & 1 & $5.00 \%$ \\
\hline
\end{tabular}

\section{Discussion}

Achillis tendon is one of the most frequently ruptured tendon and no other tendon suffers complete rupture more often ${ }^{[2,3]}$. The incidence of spontaneous complete rupture of achillis tendon has risen steadily in last few decades due to increased sedentary life style and intermittent participation in recreational sports ${ }^{[4]}$ The site of tendon rupture is usually 2 to $6 \mathrm{~cm}$ above the tendon insertion into the calcaneum, which is a relatively hypovascular area as shown by angiography studies of Lagergren and Lindholm ${ }^{[5]}$ The blood supply of the tendon is through mesotendon, maximally through anterior mesentry, which with age reduces. Age related changes in collagen cross-linking result in stiffness and loss of viscoelasticity predisposing to rupture. The practice of treating retrocalcaneal bursitis and tendoachillis tendinitis, using local steroid injection is quite common. Instead of injecting the drug in the bursa or around the tendon in mesotendon, the injection given directly in the substance of tendon, weakens collagen fibers and predisposes to rupture

In our series majority of cases i.e. 17 (85\%) were seen with in age group of 41-60. This is in correspondence with series by Juhana leppilahti, where there was maximum incidence of cases in the age group between 41-50 years.

Number of males was $15(75 \%)$ and females were $5(25 \%)$.
Probably the cause may be increased manual labour in day to day life among male population and females were exposed to less hard work.

The most common cause that leads to tendoachilles rupture in our series was by trivial or no trauma in $14(70 \%)$ patients, other $6(30 \%)$ cases due to Local steroid injection. Local Steroid injection causes increased matrix degradation and inadequate matrix synthesis leading to structural degradation ending up in tendon rupture with trivial trauma. This is more so aggravated in tendon with associated peritendinitis and tendinosis (paul Palttner and Kenneth Johnson, 1985).

In our series 8 cases were presented with in 4 weeks of trauma and 12 cases presented after 4 weeks. According to Inglis et al it was called early repair when presented with in 4 weeks and late repair when presented after 4 weeks.

This delay in presentation was

1. Negligence of patients.

2. Attributing the injury to exacerbation of previous retrocalcaneal pain.

3. Inability to diagnose the condition by attending physician.

4. Minor disability experienced by patient which gets worsened in time.

Most patients complained of pain and disturbance in gait which was mainly due to inability to plantarflex during gait cycle. All most all the patients complained of weakness in the calf.

On clinical evaluation there were skin changes are observed in patients with steroid local injection. Thompson test was positive in almost all cases but it looses its efficacy after one week because plantar flexion may result from other plantar flexors or bridging fibrous tissue. There was difference in calf muscle measurement only after prolonged period due to relative inactivity of gastrosoleus. Weakness of plantar flexion and patient being unable to stand on tip toes was seen in almost all cases, due to absence of gastrosoleus action.

According to Lagergran and Lindholm [6] tendoachilles is divided in to 3 zones. They are

Zone - I $\quad<3 \mathrm{~cm}$ from calcaneal insertion.

Zone - II $\quad 3$ to $6 \mathrm{~cm}$ from calcaneal insertion.

Zone - III $>6 \mathrm{~cm}$ from calcaneal insertion.

Most of the ruptures in our series occurred at Zone I i.e. 13 in $(65 \%)$ patients though Zone II has least vascular supply.

Of 20 cases of closed tendoachilles ruptures, we have done 8 cases of acute ruptures < 4 weeks by end to end repair by krackow sutures, 6 cases of neglected ruptures by peroneus brevis transfer with Teuffer's tecnique, 6 cases of neglected ruptures by flexor hallucis longus transfer by modified wapner technique.

Mendelbaum and colleagues ${ }^{[7]}$ showed that those undergoing direct repair lost only $2.6 \%$ of their strength when undergoing isokinetic testing and that $92 \%$ of athletes were able to return to their respective sports at a similar level at 6 months postoperatively.

Cetti and colleagues ${ }^{[8]}$ reported re-rupture rates of $1.4 \%$ and $13.4 \%$ for surgical and conservative repair, respectively. In a meta-analysis by Kellam and coworkers ${ }^{[9]}$, re-rupture rates were found to be $1 \%$ and $18 \%$ for surgical and conservative repair, respectively. Even more impressive is a study by Inglis and colleagues ${ }^{[10]}$ who reported that none of the 44 patients receiving direct repair re-ruptured, whereas 9 of 24 patients treated nonsurgically did re-rupture. 


\section{Conclusion}

The following conclusions are derived from present study.

1. Ruptures were most common in patients with heel pain with trivial and blunt injury mostly degenerative tears.

2. Most ruptures occurred in Zone I.

3. Both Flexor hallucis longus and Peroneus brevis transfers yielded good to excellent results in chronic ruptures $>4$ weeks old, and with $>3 \mathrm{~cm}$ gap.

4. End to End repair yielded good to excellent result with $<4$ weeks old and defects lessthan $3 \mathrm{~cm}$.

5. Post operative evaluation is necessary in assessing final outcome including ultrasound and isokinetic and dynamometric studies.

\section{Conflict of interests}

The authors declare no conflicts of interest.

\section{References}

1. Scheller AD, Kasser JR, Quigley TB. Tendon injuries about the ankle. Orthop Clin North Am. 1980; 11(4):801.

2. Ballas MT, Tytko J, Monnarino F. Commonly missed orthopaedics problems, Fam Physician 1998; 57:267.

3. Maffulli N. The clinical diagnosis of subcutaneous tear of the Achilles tendon. A prospective study in 174 patients. Am J Sports Med. 1998; 26:266.

4. Kvist M. Achilles tendon injuries in athletes. Sports Med 1994; 18:173.

5. Lagergren C, Lindholm A. Vascular distribution in the Achilles tendon: An angiographic and microangiographic study. Acta Chir Scand. 1958-1959:

6. Lagergren C, Lindholm A. Vascular distribution in the Achilles tendon. An angiographic and microangiographic study. Acta Chir Scand, 1958.

7. Mandelbaum BR, Myerson MS, Forster R. Achilles tendon ruptures: A new method of repair, early range of motion, and functional rehabilitation. Am J Sports Med. 1995; 23:392-395.

8. Cetti R, Christensen S-E, Ejsted, Jensen R. Operative versus non-operative treatment of Achilles te Sculco TP, et al. Ruptures of the tendo achilles: an objective assessment of surgical and non-surgical treatment. J Bone Joint Surg Am. 1976; 58:990-993.

9. Kellam J, Hunter GA, McElwain JP. Review of the operative treatment of Achilles tendon rupture. Clin Orthop. 1985; 201:80-83.

10. Inglis AE, Scott WN, Sculco TP et al. Ruptures of the tendo achilles: an objective assessment of surgical and non-surgical treatment. J Bone Joint Surg Am. 1976; 58:990-993. 